\section{How are people with mental illness dealt with in this community?}

Participants' attitudes did not correspond well with how people who are mentally ill are managed in the community (Table 2). Regardless of most participants' sympathetic attitude, only $11.7 \%$ reported that people with a mental illness are helped in their communities by giving them food and clothes and so on. Almost half of all participants reported that people with a mental illness are isolated, ignored or neglected, and over 38\% reported violent behaviour towards such people (violence included being beaten up, tied up, locked up, chased away or stoned). However, almost a third reported that people with a mental illness are taken to a hospital and $7.5 \%$ reported that they are taken to traditional healers (Table 2).

\section{Discussion}

The study utilised a cost-effective means of carrying out valuable data collection in a setting where research grants are in short supply. We acknowledge that using medical students as research workers may compromise the reliability of the study but believe that the benefits of this approach may override the limitations. Student research workers from different parts of Uganda with relevant language fluency, in a country with over 50 languages, offered a great opportunity for accessing areas that otherwise would have not been accessed in a research project without funding.

Attitudes of the population towards mental illness were mainly positive, but did not always match the community practices reported, which included unsympathetic acts and which corresponded with those reported by Kasoro et al
(2002). The differences between urban and rural populations indicate that social change and greater education have an impact on beliefs and attitudes. Education about mental illness and people who are suffering from it can lead to change, and one area where this is urgently required is in the continuing dehumanising management practices described in this study.

\section{Acknowledgements}

We would like to thank the first-year medical students (year 2002-03) at Mbarara University of Science and Technology for their help in collecting and translating the data and conducting the community survey.

\section{References}

Boardman, J. \& Ovuga, E. (1997) Rebuilding psychiatry in Uganda. Psychiatric Bulletin, 21, 649-655.

Bolton, P., Wilk, C. M. \& Ndogoni, L. (2004) Assessment of depression prevalence in rural Uganda using symptom and function criteria. Social Psychiatry and Psychiatric Epidemiology, 39, 442-447.

Hugo, C., Boshoff, D., Traut, A., et al (2003) Community attitudes toward and knowledge of mental illness in South Africa. Social Psychiatry and Psychiatric Epidemiology, 38, 715-719

Kasoro, S., Sebudde, S., Kabagambe-Rugamba, G., et al (2002) Mental illness in one district of Uganda. International Journal of Social Psychiatry, 48, 29-37.

Kigozi, F. (2005) Mental health services in Uganda. International Psychiatry, issue 7, 15-18.

Ovuga, E., Oluka, G. A. O. \& Boardman, J. (1999) Traditional healers and mental illness in Uganda. Psychiatric Bulletin, 23, 276-279.

Ovuga, E., Boardman, J. \& Wassermann, D. (2005) Prevalence of suicide ideation in two districts of Uganda. Archives of Suicide Research, 9, $321-332$.

\title{
Doctors' values, resilience and professionalism
}

\author{
Richard Williams
}

\begin{abstract}
Professor of Mental Health Strategy, Welsh Institute for Health and Social Care, University of Glamorgan, and Consultant Child and Adolescent Psychiatrist, Gwent Healthcare NHS Trust; Ty Bryn, St Cadoc's Hospital, Lodge Road, Caerleon, Newport, South Wales NP18 3 XQ, UK, email rjwwilli@glam.ac.uk
\end{abstract}

n 2001, Richard Smith, then editor of the BMJ, asked why doctors were so unhappy. He provoked a huge international response. The suggested reasons included: changes in the social structures of work; the demographic shift and difficulties in the recruitment and retention of staff; the replacement of trust with accountability; changes in relationships with people and bodies that are responsible for policy and practice; and negative media reporting.

Edwards et al (2002) concluded that 'this is an international and widespread problem' and ascribed the cause to 'a breakdown in the implicit compact between doctors and society'. At much the same time, Salter (2001) presented his analysis of the tensions in the triangle of relationships between the medical profession, society and the state in the UK.

In her Reith lectures, O'Neill (2002) provided a commentary on the impact on trust of interacting societal changes and governments' policies in the Western world. In my opinion, the latter have responded to, but also amplified, the real change in the nature of the public's trust of professionals. Salter (2001) pointed to the very rapid growth of a regulatory industry in the UK, such that all aspects of knowledge creation (research), knowledge and skill transmission (education) and application (practice) are now covered by organisations that set standards and monitor and/or evaluate their implementation. This has led to beliefs that, although there are similar developments across the world, healthcare is now more regulated in the UK than it is anywhere else.

Openness, transparency and accountability have been developed in place of reduced trust. Openness relates to processes for decision-making being open to scrutiny. Transparency refers to the basis of decision-making being overt. Accountability concerns the allocation of responsibility for decision-making, so that everyone is clear about their role and the scope of their capacity to make decisions. Although 
I welcome, these developing notions, it is noticeable that they are gaining the status of ethics principles (University of Toronto, 2005). However, Stein (2001) has written authoritatively about the limitations of accountability and critically about what lies behind the 'cult of efficiency' as a means of improving services. Trust is still required!

But has trust at the clinical level actually been eroded? Mike Shooter, past President of the Royal College of Psychiatrists, identifies a paradox. Often I hear him say that, although there is evidence in governance policy of reducing trust in professionals and the expectations of patients and the public are rising, the majority of patients continue to have good, trusting relationships with their doctors. My experiences are similar. Generally, psychiatrists are viewed very positively by their patients.

Similar findings have been presented in reports from the Picker Institute, which stands for 'patient-centred professionalism'. Its work provides a window on to the perceptions and wishes of the public about their healthcare. In one report (Hasman et al, 2006), the Institute found that most patients want to trust the clinicians they consult, and most still do. But, importantly, trust does not equate with blind faith: nowadays, people expect to see evidence that their trust is justified. Although I quote selectively, the Institute's view is that the barriers to change include a medical culture that prioritises the 'hard' sciences over what is seen as 'soft' evidence, curricular and service pressures, insufficient knowledge of how best to teach the relevant skills, and lack of effective mechanisms to spread good practice (Hasman et al, 2006).

Science has blossomed in the past 60 years, although there is much more that could be achieved with greater investment in academia and a greater focus on translational research. Now, healthcare has the potential to be increasingly effective and the promises for the future are enormous. This poses a huge challenge to the public purse that we cannot fail to face, as the Wanless reports identified (Wanless, 2002; Welsh Assembly Government, 2003). But will science eventually answer all questions and result in less need for professional judgement? In my view, and that of many others, the answer can only be 'no'.

Fulford (2004) has argued that more science brings more choices and, therefore, more decisions. It is clear from clinical experience that much of patients' and professionals' decisionmaking turns on values as well as facts. Thus, more science results in more decisions and an increasing need for the ability to work from a strong humanitarian base with a diversity of values. Fulford and I might dispute the Picker Institute's wording because we do not see 'hard' and 'soft' evidence as alternatives but as better used in synergy. Fulford has advocated that practitioners base their work on drawing together evidence-informed and values-based practice. Together, these approaches create appropriate opportunities: for openness and transparency in our work; for the responsive application of guidelines; and for patients to benefit from good relationships with doctors and individualised healthcare.

In this modern context, is professionalism a stuffy, outof-date notion based on elitism, in which people in certain occupations are seen as enjoying particular privileges? Or is professionalism essential to assuring the public and ensuring high-quality practice? Might the public suffer if it were displaced?
I see professionalism as vitally important in sustaining effective, trusting relationships between patients and practitioners and between them and representatives of the state. The essence of professionalism is exercising good judgement in sensitively advising our patients in the face of incomplete knowledge, uncertainty, complex problems and diversity of values (Williams, 2002). Clarity about how our values and ethics guide action is essential in that context. My own reviews, and those of the College's Scoping Group on Roles and Values, found that core professional values, including altruism and integrity, remain as important as ever, although the context in which they are applied has changed dramatically and will change further. The Scoping Group will be publishing its findings and thinking in a book in 2007.

I am attracted by the work of Van De Camp et al (2004). They found 'considerable inconsistency in the use of the term' professionalism and advised building the concept afresh from their thematic analysis of the literature and qualitative research. They concluded from their research that professionalism is a multidimensional concept that encompasses:

o interpersonal professionalism (prerequisite qualities for effective work with and respect for patients and other professionals)

o public professionalism (qualities relating to the demands that society makes, including ethics, knowledge and skill, which constitute expertise, and commitment to best-practice guidelines, continuity of patient care and acceptance of greater accountability)

intrapersonal professionalism (qualities and skills of judgement, flexibility, critical analysis, knowing one's limits, self-awareness and humanistic values that enable us to function well, within bodies of similar people).

Evidently, there is now a much more challenging edge to our relationships with patients, which I welcome. So, I conclude that trust is secure in those relationships, provided we work to develop our notions of what is good practice and are explicit about doing so. The Picker Institute recommends creative educational initiatives for professionals that include greater use of patients as teachers.

Over the past several years, our College has actively revisited its engagement with service users and carers, and now requires their involvement in educating trainees. It has produced a creative system for continuing professional development and 'ACP 360', a multi-source appraisal service for consultants (see http://www.rcpsych.ac.uk/crtu/ centreforqualityimprovement/acp360.aspx). Together, these and other measures are likely to go a long way to helping psychiatrists in the UK to meet the more exacting rigours of relicensing proposed by the General Medical Council (GMC).

But are these sufficient responses to the increasing concerns about how best to ensure the continuing quality and capability of doctors, including psychiatrists, or sustaining trust at political, societal and organisational levels? Sir Liam Donaldson, Chief Medical Officer for England, thinks not. In his 2006 report following the investigation into Shipman's gross crimes, he recommended a much more demanding process for revalidation, one that is split into two processes: relicensing by the GMC and recertification, probably conducted through the medical Royal Colleges.

In this circumstance of change and challenge, I was reminded by a colleague that resilience is 'the physical property of a material that can return to its original shape or position 
after deformation that does not exceed its elastic limits'. Psychological resilience can be defined as a person's capacity for adapting psychologically, emotionally and physically reasonably well and without lasting detriment to self- or personal development in the face of adversity, threat or challenge. It is not about avoiding short-term distress or deleterious responses, but about adapting to and realistic recovery from them.

I think the professions must give thought to their resilience in responding effectively, adaptively and well to the challenges that face us. I believe that psychiatrists and other doctors should afford particular priority to sustaining and developing their relationships with their patients and the public. We should also pay greater attention to maintaining our corporate resilience. I believe that rebuilding professionalism so that it remains an appropriate guide in the modern context and creating synergy between evidence-informed and values-based practice are important contributions.

I am optimistic about the future of psychiatry and mental healthcare, although, in the short and medium term, I am concerned about how we cope with the rising profile and demands of regulation. Regulation is essential but costly and, on its own, is unlikely to reassure the public. Its price must not be the erosion of relationships with patients or of creativity. It is difficult to resist the reasoned calls for relicensing and recertification but, in my opinion, both must be tempered with encouragements to practitioners to enable them to sustain and develop their relationships with the public and with patients. In this context, the new version of Good Medical Practice, the GMC's code of practice that has been effective from 13 November 2006, strikes an appropriate balance (GMC, 2006).

Of course, I write from a UK perspective. However, the evidence from Smith's enquiry (2001) is that expectations of doctors are changing across the world. So, I am keen to hear your opinions and experiences.

\section{References}

Donaldson, L. (2006) Good Doctors, Safer Patients: Proposals to Strengthen the System to Assure and Improve the Performance of Doctors and to Protect the Safety of Patients. UK Department of Health.

Edwards, E., Kornacki, M. J. \& Silversin, J. (2002) Unhappy doctors: what are the causes and what can be done? BMJ, 324, 835-838.

Fulford, K. W. M. (2004) Ten principles of values-based medicine. In The Philosophy of Psychiatry: A Companion (ed. J. Radden), pp. 205-234. Oxford University Press.

General Medical Council (2006) Good Medical Practice. GMC.

Hasman, A., Coulter, A. \& Askham, J. (2006) Education for Partnership: Developments in Medical Education. Picker Institute.

O'Neill, O. (2002) BBC Reith Lectures: lecture 1, 'A question of trust spreading suspicion'; lecture 2, 'Trust and terror'; lecture 3, 'Called to account'; lecture 4, 'Trust and transparency'; lecture 5, 'Licence to deceive'. Available at http://www.bbc.co.uk/radio4/reith2002/. Last accessed 23 October 2006.

Salter, S. (2001) Who rules? The new politics of medical regulation. Social Science and Medicine, 52, 871-883.

Smith, R. (2001) Why are doctors so unhappy? BMJ, 322, 1073-1074.

Stein, J. G. (2001) The Cult of Efficiency. House of Anansi Press.

University of Toronto Joint Centre for Bioethics Pandemic Influenza Working Group (2005) Stand on Guard for Thee: Ethical Considerations in Preparedness Planning for Pandemic Influenza. University of Toronto.

Van De Camp, K., Vernooij-Dassen, M. J. F. J., Grol, R. P. T. M., et al (2004) How to conceptualize professionalism: a qualitative study. Medical Teacher, 26, 696-702.

Wanless, D. (2002) Securing Our Future Health: Taking a Long-Term View. HM Treasury. Available at http://www.hm-treasury.gov. uk/media/A99/D2/letter_to_chex.pdf. Last accessed 23 October 2006.

Welsh Assembly Government (2003) The Review of Health and Social Care in Wales. Summary available at http://www.wales.nhs. uk/documents/wanless-summary-e.pdf. Last accessed 5 November 2006.

Williams, R. (2002) Complexity, uncertainty and decision-making in an evidence-based world. Current Opinion in Psychiatry, 15, 343-347.

NEWS AND NOTES

\section{Middle East War}

The College President and the Director of International Affairs wrote to all College members in the Middle East Division to pledge support and offer help with the effects of the recent violence on the civilian population. Professors Hollins and Ghodse also wrote to the Presidents of the Lebanese, Israeli and Palestinian Psychiatric Associations and the World Psychiatric Association calling on the governments involved, on the United Nations and on the international community for the immediate cessation of fighting and a lasting resolution to this conflict.

\section{WHO national mental health counterparts}

The ninth annual meeting of the World Health Organization (WHO) European national counterparts took place on 30 March to 1 April 2006, hosted by Greece, in Chania. The aim of the meeting was to offer a forum for the $\mathrm{WHO}$ to report back on progress achieved after the January 2005 meeting of ministers in Helsinki and for national counterparts to discuss the mental health priorities in their countries and reach an agreement on future activities in partnership with the WHO.

Participants identified common challenges across countries and challenges specific to different stages of development of national mental health systems.

Future work in partnership between countries and the WHO will include cross-country projects and country-specific projects focused on a set of agreed priority areas for future collaboration with the $\mathrm{WHO}$, as follows:

o service development

o workforce

financing

knowledge dissemination

o strategy development and legislation.

Information supplied by Dr Matt Muijen, Regional Adviser for Mental Health at the European Regional Office of the WHO 